\title{
Informação-afeto: real sem ser atual, ideal sem ser abstrata
}

\begin{abstract}
Resumo
Este trabalho trata do conceito de informação-afeto e suas implicações para a compreensão de memória e tempo na ciência da informação, sendo uma alternativa à noção da informação como coisa. A leitura deleuzeana da compreensão do tempo de Bergson destaca as três sínteses do tempo - o hábito, a memória pura e o eterno retorno do diferente - para afirmar a afecção do passado e do futuro no tempo presente. Nessa perspectiva, coexistem passado, presente e futuro, sendo as inovações devidas às bifurcações no tempo intensivo. Assim, repetição e diferença são vistas como afirmações na memória dentro dos arquivos, das bibliotecas e dos museus. Explica o conceito de afeto em relação à ideia e diz o documento como ser representativo e afetivo.
\end{abstract}

Palavras-chave: informação-afeto; afeto; memória; tempo.

\author{
Denise Viuniski da Nova Cruz \\ Doutoranda em Educação e \\ Professora da Universidade do \\ Vale do Itajaí - Brasil. \\ novacruz@novacruz.med.br
}

\section{Solange Puntel Mostafa} Doutora em Educação pela Pontifícia Universidade Católica de São Paulo. Professora da Universidade de São Paulo Brasil.

\section{Para citar este artigo:}

NOVA CRUZ, Denise Viuniski da; MOSTAFA, Solange Puntel. Informação-afeto: real sem ser atual, ideal sem ser abstrata. Revista PerCursos. Florianópolis, v. 15, n.29, p. 39- 56. jul./dez. 2014. 


\title{
Information-affection: real without being actual, ideal without being abstract
}

\begin{abstract}
This paper is concerned with the concept of information-affect and its implications for understanding memory and time in information science, being an alternative to the notion of information as a thing. The deleuzean reading of Bergson's understanding of time highlights three syntheses of time - the habit, pure memory and eternal return of different - to assert the affection of past and future in present time. From this perspective, past, present and future coexist, and the innovations are due to bifurcations on the concept of intensive time. Thus, repetition and difference are seen as statements in memory of archives, libraries and museums. It distinguishes the concept of idea (representative) from that of affect (non-representative) to consider the document as being representative and affective at the same time.
\end{abstract}

Keywords: information-affection; affection; memory; time. 


\section{Introdução}

Temos aprendido com Gilles Deleuze e Félix Guattari (2007) que a filosofia não é um ato de reflexão como supõe o senso comum quando se depara, por exemplo, com a imagem do Pensador de Rodin. Analisar os problemas da vida ou procurar os fundamentos de algo, seja na forma de princípios ou de processos, não é a tarefa da filosofia. A filosofia, para esses autores, está comprometida com nossa existência, mas ela não tem por tarefa refletir sobre nossos problemas, se por reflexão entendemos o movimento de olhar para trás a fim de compreender o que se passou.

Mais inventiva, a tarefa filosófica impõe-se como criação de conceitos e os conceitos, portanto, são sempre filosóficos. A filosofia também não tem por tarefa comunicar algo, uma vez que a comunicação supõe atingir um consenso das opiniões, e a filosofia não busca o consenso e nem se preocupa com as opiniões. Assim, a filosofia, ao contrário do universal, do consenso ou da doxa, opera por singularidades.

Os conceitos filosóficos são, portanto, singulares, particulares e relativos a problemas específicos da existência - do vivido - impondo a eles uma sempre nova direção. Por isso, Deleuze e Guattari (2007) afirmam que os conceitos filosóficos são absolutos e relativos ao mesmo tempo. São relativos a outros conceitos, uma vez que não existem conceitos simples ou isolados, são sempre situados em um plano que os abriga (Plano de Imanência). Portanto, os conceitos são também relativos a esse plano e aos problemas que se supõe que eles devam resolver. Mas, também, são absolutos pelas condições que impõem aos problemas. Para os pensadores franceses, os conceitos da filosofia são os que fazem os movimentos absolutos no mundo.

Assim, Informação-afeto trata de um conceito filosófico e pode, portanto, ser considerado como o outro lado da informação-coisa; algo que vai além da informação como ideia. Se a informação-coisa é a informação registrada, como ideia, há outra face que escapa a qualquer registro, apesar de ser real. Queremos propor essa nova direção ao tema Informação, Memória e Sociedade, pois, como demonstrado na pesquisa de Oliveira e Rodrigues (2011), a questão da memória estudada pela ciência da informação relaciona-se com a informação registrada, isto é, com os documentos "[...] nos mais 
variados suportes, como elementos de relevância para a memória social, em vários níveis: local, regional ou nacional" (OLIVEIRA; RODRIGUES, 2011, p. 325).

É importante também destacar a expressão “memória social”, pois é dela que trata a maioria dos trabalhos. O tema da memória estudado pela Ciência da Informação está, então, relacionado ao objeto informação-registrada e serve aos propósitos de "reconstrução da memória e formação de identidades a partir desses registros, o que exige sua organização, preservação e divulgação" (OLIVEIRA; RODRIGUES, 2011, p. 325). Ainda, esclarece a pesquisa citada que a preservação dessa memória está associada com as instituições de guarda ou locais de memória como os arquivos, bibliotecas, museus e centros de documentação.

São relevantes, portanto, os estudos mencionados na referida pesquisa a qual se identifica por tratar de estudos relacionados à memória social e à sua reconstrução, mais do que relacionados à memória humana ou à memória artificial. Ao tema da memória social estão relacionados termos como "informação, instituição, documento, sociedade, preservação, identidade, cultura, ciência, história, conhecimento" (OLIVEIRA; RODRIGUES, 2011, p. 318). Esse conjunto de termos parece-nos coerente e faz jus à memória social tanto quanto os que apontam para uma construção ou reconstrução, preservação, conservação, etc.

Os locais nos quais os cientistas da informação exercem suas práticas arquivos, bibliotecas e museus - considerados "lugares de memória", bem como a memória das instituições, resultam em apropriações dos conceitos de memória social e memória coletiva e no emprego de múltiplas extensões, tais como: instituições de memória, centros de memória, arquivos de memória e entidade de memória. Ainda referindonos às extensões, são constantes as referências a uma dinâmica da memória possibilitada pela informação registrada: construção, reconstrução, formação, manutenção, recuperação, preservação, conservação, valorização, incorporação, interação, exclusão e destruição da memória. (OLIVEIRA; RODRIGUES, 2011 p. 323).

Outra importante determinação dos estudos brasileiros realizados sobre memória é que, em sua maioria, são utilizados os referenciais teóricos da História e da Sociologia. Os autores mais citados nas abordagens do tema memória são historiadores como Jacques Le Goff, Ecléa Bosi ou Pierre Nora e sociólogos como Maurice Halbwachs ou 
Michel Pollack. Também é mencionado o filósofo Henri Bergson - apesar de que ficamos com a impressão de que ele é utilizado em menor escala que os historiadores e os sociólogos.

Talvez possamos iniciar aqui nossa reflexão sobre a informação-afeto. Apesar de o afeto ser um conceito filosófico de Espinosa - o polidor de lentes do século 17 - não estaríamos traindo esse conceito se o traduzíssemos por Informação-duração para aproximarmo-nos do pensamento bergsoniano, já conhecido dos cientistas da informação nas pesquisas sobre memória.

\section{Prolegômenos de informação, memória e sociedade}

Uma de nossas questões poderia ser: por que recorrer a Deleuze [e Guattari] para tratar de Informação, Memória e Sociedade e não apenas a Bergson já que Deleuze abraça várias teses bergsonianas sobre o tempo? De fato, tanto Bergson quanto Deleuze podem ser lembrados como filósofos do tempo, mas também como filósofos que colocaram as questões sobre o Ser ou sobre a Existência.

Como é que a vida acontece? O que faz algo aparecer no mundo? Como surge o novo, o impensável, o impensado? Além de Bergson, Deleuze reconhece, ainda, outros filósofos com essa mesma preocupação, como Espinosa, Foucault e Nietzsche. Por exemplo, no texto em homenagem a Michel Foucault chamado $O$ que é um dispositivo (DELEUZE, 1990), Deleuze comenta que uma filosofia dos dispositivos é uma mudança de orientação que se separa do eterno para apreender o novo. O autor reconhece também que perguntar pelo Ser sem recurso ao eterno ou à eternidade é uma questão nascida no século XX: “como é que é possível no mundo a produção de algo novo?” (DELEUZE, 1990).

A obra de Bergson é considerada por Deleuze (2004, p. 32) um "verdadeiro canto em louvor ao novo, ao imprevisível, à invenção". De fato, o texto dedicado a Bergson no livro Ilha Deserta e outros textos (DELEUZE, 2004) inicia elogiando as novas verdades, a nova distribuição dos problemas e o recorte extraordinário trazido pelos conceitos 
filosóficos de Bergson como as noções de duração, memória, impulso (élan) vital e intuição.

No mesmo livro, Deleuze apresenta um texto intitulado A concepção da diferença em Bergson no qual lemos o filósofo afirmar que "a noção de diferença deve lançar certa luz sobre a filosofia de Bergson, mas, inversamente, o bergsonismo deve trazer a maior contribuição para uma filosofia da diferença" (DELEUZE, 2004, p. 34).

Se Deleuze pôde reconhecer Bergson e outros filósofos com a mesma preocupação ontológica da fundação do mundo sem passar pelo céu, é porque essa também era a sua preocupação filosófica. Estamos, portanto, diante de uma novidade da filosofia do século XX ao analisar as contribuições de Bergson e Deleuze para o tema da Memória e do Tempo. Novidade que se espraia também em outros filósofos, mas que, em Bergson e em Deleuze, assume uma importância fundamental, pois é no tempo que ambos encontram a novidade: Bergson, por meio da análise de um tipo singular de multiplicidade formada pela sucessão de nossos estados de consciência; e Deleuze, através das três sínteses do tempo que ele descreve em Diferença e Repetição (DELEUZE, 1998): a diferença surge da repetição através de três sínteses do tempo: o hábito, a memória pura e o eterno retorno do diferente, conceitos para os quais Deleuze mobiliza as filosofias de David Hume, Henri Bergson e Nietzsche, respectivamente.

Para Deleuze, as coisas repetem-se primeiro como hábito (memória-hábito tal como David Hume já havia explicado: o sol sempre nascerá amanhã) e duram (memóriaduração de Bergson compreendendo a relação entre virtual e atual: o passado existe somente enquanto e porque incide no presente), acrescentando ainda a essa estrutura ontológica do Ser uma noção mais forte de devir: roubando de Nietsche o conceito de eterno retorno, criando o novo conceito de eterno retorno do diferente, na terceira síntese do tempo.

Assim, o que é de extrema relevância para o campo da guarda da informação é a noção de que o que nos fica de um tempo passado (que já não existe mais) é tão somente aquilo que dura, que permanece, que continua afetando o tempo presente. Eis aqui o conceito de durée (duração) de Bergson, fazendo sentido para aquele que trabalha com 
museus, arquivos, coleções e documentos. Enfatizemos, aquilo que dura em nós, que afeta nosso presente é tudo que existe de um tempo chamado passado.

Filósofos do século XX, ambos Bergson e Deleuze, explicaram as dificuldades envolvidas no entendimento da "novidade": para o primeiro, o problema era a espacialização do tempo deixando sem solução "os paradoxos do tempo" (como a flecha imobilizada no espaço-tempo ou nos momentos sucessivos dos passos de Aquiles que nunca alcança sua adversária tartaruga). Ao invés, Bergson apresenta-nos um conceito de tempo no qual diferentes "tempos" coexistem.

Já Deleuze atribui a imagens dogmáticas do pensamento e à cognição certos processos que nos impedem de acolher tal "novidade”. A novidade é o tempo, a duração, a diferença, que, em Bergson, aparece em sua análise sobre a evolução das espécies (a sobrevivência das mais fortes não explica o surgimento de novas espécies - a diferença aparece com o tempo) e, em Deleuze, a diferença será a marca de toda a sua filosofia permitindo ao filósofo criar conceitos em vários campos e problemas do seu tempo, como na questão da linguagem, na literatura, na pintura, no cinema, bem como em conceitos filosóficos criados para as ciências e as tecnologias.

Bergson pergunta-se por que não pudemos pensar de maneira satisfatória a mudança, a criação, a evolução, se tudo muda e evolui na duração. Mas, para Deleuze, ainda é preciso perguntar pelo funcionamento do Ser. Diz-se que Bergson renova a metafísica, restaura-a, por assim dizer, com sua filosofia da duração; enquanto Deleuze instaura ou desenvolve uma ontologia do devir, da mudança, da diferença - tendo Bergson, mas também Nietzsche, Simondon e Whitehead como aliados ou pensadores do devir, do tornar-se, da transformação e da metamorfose.

A cada nível da reflexão deleuzeana, a "novidade" é razão de ser da sua filosofia que se contrapõe a uma filosofia da identidade e da representação. Pensar é experimentar e toda experimentação testa o novo, seja na filosofia, seja no terreno prático em que a ética torna-se uma filosofia dos encontros. O direito vale mais pela jurisprudência do que a lei estabelecida. No campo social, haverá agenciamentos de desejo contra os agenciamentos de poder. Se Deleuze escreveu monografias sobre vários 
filósofos na sua primeira fase iniciada nos anos cinquenta, é no livro Diferença e Repetição do final dos anos sessenta que ele desenvolve a sua própria filosofia da diferença, incorporando as contribuições de Bergson e Nietzsche em uma compreensão mais dinâmica do devir e da relação do virtual com o atual.

\section{A Memória e o tempo}

O tempo, como objeto metafísico, tem sido considerado por pensadores desde a Grécia antiga. Três termos os gregos atribuíram para discorrer sobre o tempo: kronos, aion e kayros. Kronos, o tempo objetivo, trata do deus que incansavelmente devora seus filhos. O tempo do relógio, linear, de divisão do espaço, da sucessão. Essa imagem de tempo não consegue explicar como um instante de dor é incomensuravelmente maior que um instante de prazer. Também, não consegue resolver os insolúveis paradoxos do estádio, de Aquiles e da tartaruga e da flecha lançada ao ar. Se o tempo trata de divisões cada vez menores de espaço percorrido, então, se a tartaruga sair uma fração desse tempo à frente de Aquiles, este jamais alcançará o lento adversário, pois, cada vez que Aquiles chegar onde a tartaruga estava, ela já não estará mais ali, mesmo que se trate de um espaço infinitamente minúsculo. Tempo cronológico permanece sendo nada mais que uma abstração útil.

Aion trata do tempo das intensidades, um tempo subjetivo. Das variações de intensidade e kayros é o termo reservado para a oportunidade, tempo fugidio, "tempo das águas de março, das promessas de vida..." '. No lugar de uma linha contínua, de uma lógica linear, Deleuze teoriza um tempo redemoinho, um fluxo de tempo.

[...] ao invés de uma linha de tempo, tem-se um emaranhado de tempo, em vez de fluxo, uma massa; em lugar de rio, um labirinto; não mais um círculo, porém um turbilhão em espiral; não uma ordem do tempo, mas variação infinita, nem mesmo uma forma de tempo, mas um tempo informal, plástico (PELBART, 2004 apud HUR, 2013, p. 180).

\footnotetext{
${ }_{1}$ Menção à canção de Tom Jobim Águas de Março. Disponível em: <http://www.vagalume.com.br/elisregina/aguas-de-marco.html>. Acesso em: 20 set. 2014.
} 
Algo muito mais parecido aos labirintos de Jorge Luis Borges, onde diferentes tempos convivem, passado e futuro incidindo no presente. Como insiste Borges (1999), um presente que é singular, pertence a cada um, não se pode enquadrar em uma noção universal de tempo. O mais importante, para nossa teorização, é que o tempo linear, cronológico, pressupõe uma relação de causa-consequência, uma teleologia tão cara aos processos representativos da informação que se dão dentro da noção de História.

Acreditamos em tempo intensivo, em fluxos de tempo, em variação de potência. Fora da História, em um entretempo, capaz de bifurcar sempre, criando o novo, fora dos ditames da razão moderna que impõe uma teleologia inflexível e de difícil escapatória. Por isso, Deleuze e Guattari vão teorizar as linhas de fuga, as entradas e saídas múltiplas de um método aberto, dito rizomático.

Quem melhor teorizou essa noção de intensidade, de subjetividade de passado e presente incidindo no tempo presente foi o filósofo francês Henri Bergson. Para Bergson, o tempo é duração, sem a relação estanque e sucessiva do tempo linear. Passado e presente coincidem, o passado afeta e incide no presente. Aliás, do futuro pode-se dizer o mesmo. É fato que o futuro ainda não existe. Entretanto, por hábito e crença, admitese que muito provavelmente o dia vai amanhecer e o avião sairá no horário esperado. Hábito e crença. Nada mais do que isso. O futuro existe, tão somente, na medida em que incide (afeta) o presente. Passado e futuro, então, pode-se dizer, atualizam-se no presente. A lembrança e o plano futuro constroem-se na percepção do presente. $O$ importante nessa noção do tempo é a possibilidade do aparecimento do novo, da bifurcação: duração entendida como o fluxo do novo, do diferente, do inesperado. Do fora do tempo.

Bergson afirma o tempo como duração e a duração como memória, como fluxo intensivo, como variação contínua. Assim, os acontecimentos seriam mais como o fio que está escondido pelas pérolas de um colar. Não há salto de uma pérola a outra e sim variação contínua, duração-memória que dá sentido a tudo que acontece: tudo sempre novo, sempre possível. 
Para explicar essa noção de tempo, Bergson imaginou um modelo de cone invertido, de base $A B$, em que o vértice $(S)$ tangencia o plano do presente. Na área compreendida pelo cone, encontra-se o passado - múltiplos lençóis, como Deleuze teoriza no seu livro Cinema-2: a imagem-tempo (2007) - e no vértice as pontas do presente. Nessa imagem, há um fluxo dos lençóis do passado, puxados pelas pontas do presente, marcando a memória como uma possível atualização das lembranças virtuais. Lembranças estas, que nesse conceito, coexistem com 0 presente atualizado, representando sempre um fluxo do virtual ao atual (real e ideal). "A lembrança coexiste com aquilo de que ela é lembrança, coexiste com a percepção correspondente; o presente é tão somente o grau mais contraído da memória, é um passado imediato" (DELEUZE, 2007 p. 119).

Com essa concepção de tempo duração, de memória como atualização de lembranças passadas que afetam o presente sempre e de novo, Deleuze soma à noção de eterno retorno de Nietzsche. Se o filósofo alemão teorizou o eterno retorno, Deleuze afirma a diferença: tudo retorna ao presente, mas atualizado, tudo sempre retorna, mas retorna diferente. O magnífico dessa teorização é a possibilidade de vislumbrar a memória não como passado fixo, mas sim como atualização sempre renovada de um futuro porvir.

\section{Informação, Memória e Sociedade}

A relação entre Informação e Memória remete quase que diretamente ao texto do historiador Pierre Nora (1993) para pensar as bibliotecas, os arquivos e os museus como “lugares de memória". O autor estabelece uma tensão entre memória e história já no título do trabalho Entre história e memória: a problemática dos lugares. O texto é uma apresentação de um projeto em vários volumes destinados a fornecer um inventário dos lugares e dos objetos nos quais se encarna a memória nacional francesa. Esse texto teve, também, repercussão na construção da memória nacional em outros países como Alemanha, Itália, Holanda e Espanha. É, com efeito, um texto também muito citado no Brasil em várias áreas relacionadas à memória e à construção/preservação do patrimônio 
cultural. Mas, em que pese o extraordinário sucesso desse texto introdutório de uma obra comemorativa dos feitos de um país, eis que Nora, um editor dos mais respeitados na França, desagradou profundamente parte dos historiadores ao estabelecer aquela tensão entre memória e história, ao dizer que construímos esses lugares de memória por já tê-la perdido. Veremos surgir outros projetos editoriais e outras introduções contrapondo o projeto de Nora, a exemplo do jovem americano Rothberg (2010), preferindo ir dos lugares de memória aos nós de memória.

Entretanto, preferimos entender a tensão entre memória e história apontada por Nora como a tensão entre o virtual e o atual (MOSTAFA; SILVA; SANTARÉM, 2012), vendo nela mais uma ressonância bergson-deleuzeana, pois ora o autor fala em memória como absoluto, ora como lembrança, ambas contidas no cone invertido de Bergson, sobre o qual Deleuze tece quatro comentários nos livros de cinema (COSTA, 2011). A memória como absoluto aproxima-se da base do cone e as lembranças que nos habitam representam o vértice mais contraído do presente. Para Nora, o que constitui os lugares de memória são estes vai e vem entre as lembranças e o passado puro. Os lugares de memória são "[...] momentos de história arrancados do movimento da história, mas que lhe são devolvidos" (NORA, 1993, p. 13).

As explicações deleuzeanas sobre o "acontecimento" também problematizam a história tradicional, pois o tempo do acontecimento está fora da história. Mas, quiçá, nenhum acontecimento prescinda da história, expressa na bela expressão de Rodrigues (2009): "filosofia da diferença e da repetição". Os monumentos comemorativos, as bibliotecas e os museus são lugares da diferença e da repetição. Para Whitehead (apud SHAVIRO, 200-), esse matemático filósofo que Deleuze e Bruno Latour tanto apreciam, até o obelisco egípcio na beira do rio Tâmisa em Londres é um "acontecimento" (SHAVIRO, 200-). Mesmo a pedra, mesmo o monumento acontece o tempo todo: é devir, é acontecimento e está em permanente transformação. Contudo, como explica Deleuze na primeira síntese do tempo apoiado em David Hume, 
repetição não estará no fato de que não se pode falar em repetição a não ser pela diferença ou mudança que ela introduz no espírito que a contempla? (DELEUZE,1998, p.127)

Se a repetição se desfaz à medida que se faz, não seria o caso de dizermos que a história se faz à medida que se desfaz?

\section{O Afeto e a Informação}

Existem as ideias e os afetos. As considerações feitas a partir deste ponto referemse à aula proferida por Gilles Deleuze (2009), no seu curso sobre Espinosa, ministrado em Vincennes entre 1978 e 1981, a partir da sua leitura da Ética (2009). Talvez a maneira mais simples de explicar-se a diferença e a complementaridade das ideias e dos afetos seja pensar em uma refeição predileta. As ideias para o preparo da refeição são essenciais, têm materialidade, cabem dentro de um estilo, representam escolhas. Ingredientes, tempero, tempo de preparo. O afeto, por sua vez, é o prazer de comer a refeição preparada pela mãe. Para sempre o cheiro do tempero da cozinha da mãe vai habitar o consciente e o inconsciente de cada um. Uma fração de segundo que sejamos expostos a um cheiro familiar traz-nos, imediatamente, o afeto daquela refeição que sempre esteve ali. Os ingredientes, os temperos, a receita são a ideia e o estilo. $O$ afeto é algo com pouca realidade formal, difícil de explicar (pela razão cognitiva), fácil de sentir. Cozinhar como gesto de amor, como afeto, como arte. É humana e universal essa capacidade de afetar e de ser afetado. Assim, o afeto anda ao lado da informação como representação, como ideia. A ideia informa, tão somente; o afeto marca, dura, permanece. Usando palavras de Espinosa: o afeto faz variar a nossa potência de existir.

Uma vez marcado por um afeto, afetado para sempre. Esse é o argumento apresentado para a o campo da ciência da informação. A informação como potência afetiva. Tratar o objeto-informação como quem prepara uma refeição predileta, como quem pinta uma obra de arte, como quem compõe ou ouve uma sinfonia. Informação capaz de afetar existências, de movimentar o mundo. 
Informações-afeto trazem em si a capacidade de afetar - e de serem afetadas por - pessoas, sentimentos, ideias, outros processos de informação. Esse novo conceito segue o caminho teórico do afeto de Espinosa, abordado a partir das considerações que Gilles Deleuze faz acerca dos conceitos propostos por Espinosa no século 17. Baruch de Espinosa viveu na Holanda de 1632 a 1677 e sua principal obra é intitulada - tão oportunamente - Ética. É nesse livro que o filósofo setecentista vai conceituar os seres a partir das suas capacidades de afetar e de ser afetados e não como todos os demais filósofos por suas essências (ESPINOSA, 2009).

Para Espinosa, os seres e as coisas existentes diferenciam-se entre si pelas suas capacidades de afetar e serem afetados. Simples assim. A vida seria uma experiência transcorrida em uma variação contínua de afetos. Dependendo da afecção provocada pelos encontros que se proporcionam durante a existência, passamos de um estado de vibração dado, de uma intensidade afetiva, para outro. Variações quantitativas de intensidades afetivas decorrentes dos encontros que estabelecemos nos trajetos da existência. Encontros estes com as coisas, com os pensamentos, com os corpos, com o outro. Afinal, tudo se dá - na vida - nesta relação do "eu” com o outro.

Se o encontro do eu com o outro aumenta nossa potência de existir, Espinosa fala de Alegria, de um encontro, de um afeto alegre. Se o encontro causa uma diminuição na potência de vida, uma variação negativa da intensidade do conatus (esforço de cada ser de perseverar no seu ser), o filósofo chama de Tristeza, de um encontro triste.

Como explica Deleuze (2009, p. 20), existem dois termos em latim utilizados por Espinosa para se referir ao afeto: affectio e affectus. Em português também dispomos de duas palavras para expressar esses dois conceitos. O primeiro termo, affectio, traduz-se por afecção (a capacidade de afetar e ser afetado); e o segundo, affectus, trata do afeto, do sentimento (da variação de intensidade de potência de vida), propriamente dito.

O que parece ser uma conclusão tão singela, como na realidade é, passa por uma complexa elucubração filosófica do maior interesse para a ciência da informação. Há basicamente dois modos de pensamento aplicáveis à vida em geral: o modo de pensamento representativo e o modo de pensamento não representativo. $O$ primeiro 
leva em consideração as ideias, o segundo os afetos. Assim, explica Deleuze (2009), didaticamente, a questão: "Ideia é um modo de pensamento que representa alguma coisa. Por exemplo, a ideia do triângulo é o modo de pensamento que representa o triângulo". É o que também se denomina "realidade objetiva". "A ideia, quando representa alguma coisa, é dita ter uma realidade objetiva" (DELEUZE, 2009, p. 24).

"Chama-se de afeto todo o modo de pensamento que não representa nada" (DELEUZE, idem, p. 26). Afetos, sentimentos, ansiedade, angústia, amor trazem em si a ideia de uma coisa que os gera, um objeto de amor, uma ideia que provoca medo ou esperança. Mas o afeto em si, como tal - como afeto - não representa nada, “estritamente nada".

Todo o desejo - o querer, a esperança, o medo de não alcançar - está dado num objeto de representação, em uma ideia; entretanto, o afeto em si, o querer e não querer; a esperança e o medo - em si - nada representam, são afetos.

Antes de Espinosa, havia um "primado da ideia sobre o afeto" porque se considerava que havia de se ter uma ideia, por mais indeterminada que fosse, do objeto relativo ao afeto experimentado. Assim, apesar de haver uma primazia cronológica da ideia (pensamento representativo) sobre o afeto (pensamento que nada representa), "seria um contrassenso, inteiramente desastroso, o leitor transformar este primado lógico em redução" (DELEUZE, 2009, p. 22). Sim, há uma anterioridade do objeto em relação ao afeto. Não, o afeto e a ideia da coisa não se referem ao um mesmo objeto de pensamento. Uma coisa é a ideia do objeto que se ama, outro modo de pensamento é o amor. Uma coisa não se reduz à outra.

Indo adiante, na argumentação filosófica, há de se considerar que a ideia, além de sua realidade objetiva, também tem uma realidade formal. Ou seja,

[...] é a realidade da ideia enquanto ela é em si mesma alguma coisa. A realidade objetiva da ideia de triângulo é a ideia de triângulo enquanto representando a coisa triângulo; mas, a ideia de triângulo, em si mesma, é alguma coisa também; por outro lado, enquanto ela é alguma coisa, eu posso formar uma ideia desta coisa[...]. (DELEUZE, 2009, p. 22) 
Essa é a realidade formal de uma ideia. É o grau de realidade formal (a forma que uma ideia possui) que Espinosa determina como grau de realidade ou de perfeição de uma ideia. Deleuze explica que cada ideia tem seu grau de realidade e que este está relacionado ao objeto que representa, mas não se reduz, não se confunde com o objeto em si.

A realidade formal da ideia, ou o grau de realidade ou de perfeição de uma ideia encerra em si o seu caráter intrínseco, enquanto a realidade objetiva da ideia (a relação com o objeto que representa) consiste em seu caráter extrínseco. Para facilitar a compreensão, Deleuze traz os exemplos da ideia de Deus e da ideia de uma rã. Ambas as ideias têm uma realidade objetiva específica, uma representa Deus e outra a rã, sendo este seu caráter extrínseco próprio. Entretanto, a ideia de rã traz um caráter intrínseco (realidade formal) menor, que a ideia de Deus que possui um grau de realidade ou perfeição intrínseca muito maior que a ideia de rã (coisa finita).

Então, há, inicialmente, dois modos de pensamento: o representativo: ideia; e o não representativo: afeto. Entretanto, a ideia possui duas realidades, uma objetiva que faz a relação direta com o objeto representado e outra realidade formal (que parte do suposto que se pode ter uma ideia de uma ideia). A realidade formal, ou caráter intrínseco relaciona-se com o grau de perfeição de uma ideia (como, por exemplo, a ideia de Deus). Isso nos traz de volta à Espinosa e suas definições de afeto.

Para Espinosa (2009, p. 25), nós, seres humanos, somos todos "autômatos espirituais; isto quer dizer que são mais as ideias que se afirmam em nós do que nós que temos as ideias". A existência não passaria, então, de uma sucessão contínua de ideias, alguma coisa em cada um de nós, o tempo todo não para de variar. Para Deleuze, é essa a conclusão que se chega a partir dos conceitos de Espinosa. Durante a vida, a cada momento, nos encontramos com outros corpos, coisas e pensamentos. Cruzamos com alguém na rua e a ideia dessa pessoa, com sua realidade objetiva e formal nos afeta, fazendo com que passemos de um estado de força de existir (vis extendi) ou de potência de agir (potentia agendi). O tempo todo, em variação contínua, alteramos nossas forças e potências. Para Espinosa, viver é variar continuamente a potência de agir e a força de existir. E mais, que essa variação (de agir e de existir) não depende - inteiramente - de 
uma comparação de ideias. Isso significa que, para Espinosa, sob as lentes de Deleuze, por não se reduzirem a uma só coisa (a ideia o afeto); o afeto em si pode ser constituído pela variação de um grau de perfeição ao outro que, mesmo que provocado por uma ideia (inicialmente) não depende da ideia da coisa para existir, trata-se, afinal, de um afeto (pensamento não representativo).

Encontros alegres provocam variações positivas na potência de agir e na força de existir. Encontros tristes, ao contrário, diminuem tais potências. "E, sobre esta linha metódica da variação contínua constituída pelo afeto, Espinosa vai assinalar dois polos: alegria-tristeza" (DELEUZE, 2009, p. 27). Então, como explicado anteriormente: a vida seria uma variação de intensidade - quantitativa - dessas forças. Vida como potência de existir, vida como força de agir. Vida que varia da tristeza à alegria, continuamente, dependente dos encontros da existência, das ideias que se fazem desses encontros. Vida dependente dos afetos, da capacidade de afetar e de ser afetado.

Outra maneira de expressar os afetos de alegria e de tristeza que Espinosa utiliza em sua Ética é nomear os afetos alegres de ação e os tristes de paixão. Os afetos ativos levam-nos a aumentar as forças dos atos e a potência da vida. As paixões são afetos tristes, passivos, diminuem a potência da existência. Toda vez que um encontro dá-se, entre dois corpos, pensamentos, ideias, enfim: encontros... Toda vez que um encontro dá-se, por exemplo, no encontro entre o leitor e o livro, o expectador e o filme; entre o visitante do museu e a obra de arte, existem duas possibilidades: ou o encontro será ativo, fazendo as potências de vida e a forças de agir variarem positivamente, configurando-se em um encontro alegre; ou a potência do encontro acaba sendo triste, uma paixão, e as intensidades e forças variam negativamente: tristeza. E isso, muitas vezes, é fundamental compreender, independe da ideia imediata (pensamento representativo) por trás da visita ao museu ou à biblioteca, do motivo do encontro. Tratase, como explicado acima, de puro afeto.

Capacidade de afetar e de ser afetado. É o que define os seres. É o que define as pessoas, as coisas os objetos da informação. Capacidade de afetar e de ser afetado. De variar a potência de vida e de existência. Documentos, obras de arte, livros - informação e memória - como variações intensivas da alegria de viver, da potência de se estar vivo. 
Fazer uso desses objetos como puro afeto. Como obra de arte, com sua capacidade de tocar em algo que não passa, tão somente, por ideias, trata mais do que objetos representativos. Toca na esfera dos afetos, apesar de, como visto anteriormente, ter realidade formal e, portanto, passíveis de serem desenvolvidos, aprimorados, alargados, experimentados e passados adiante.

\section{Referências}

BORGES, Jorge Luis. Nova refutação do tempo. In: . Outras inquisições: obras Completas, volume II. São Paulo: Globo, 1999.

COSTA, Silvano João da. Bergson-Deleuze nos conceitos de cinema. In: MOSTAFA, S. P.; NOVA CRUZ, D. V. da Deleuze vai ao cinema. Campinas: Alínea, 2011.

DELEUZE, Gilles. Cinema 2 : a imagem-tempo. São Paulo: Editora Brasiliense, 2007.

DELEUZE, Gilles. Cursos sobre Espinoza: Vincennes, 1978-1981. Fortaleza: EDUECE, 2009.

DELEUZE, Gilles. Diferença e repetição. Rio de Janeiro: Graal, 1998.

DELEUZE, Gilles. Ilha deserta e outros textos. São Paulo: Iluminuras, 2004.

DELEUZE, Gilles. ¿Que es un dispositivo? In: . Michel Foucault, filósofo. Barcelona: Gedisa, 1990, p. 155-161.

DELEUZE, Gilles; GUATTARI, F. O que é a filosofia? São Paulo: Editora 34, 2007.

ESPINOSA, Baruch de. Ética. Tradução de Tomaz Tadeu. Belo Horizonte: Autêntica, 2009. HUR, Domenico Uhng. Memória e tempo em Deleuze: multiplicidade e produção. Athena Digital , v.13, n., jul. p.179-190, 2013.

MOSTAFA, Solange Puntel; SILVA, Márcia Regina da; SANTARÉM SEGUNDO, José Eduardo. História cultural e ciência da informação. In: SANTARÉM SEGUNDO, José Eduardo; SILVA, Márcia Regina; MOSTAFA, Solange Puntel. Os pensadores e a ciência da informação. Rio de Janeiro: E-paper, 2012.

NORA, Pierre. Entre memória e história: a problemática dos lugares. São Paulo: PUC-SP, 1993. (Projeto História, n. 10.) 
OLIVEIRA, Eliane Braga de; RODRIGUES, Georgete Medleg. O conceito de memória na Ciência da Informação: análise das teses e dissertações dos programas de pós-graduação no Brasil. Rio de Janeiro, Liinc em Revista, v. 7, n. 1, mar. p.311-328, 2011.

ROTHBERG, Michael. Introduction: between memory and memory: from lieux de mémoire to noeuds de mémoire. JSTOR (Journal Storage) n. 118/119, p.3-12, 2010.

SHAVIRO, Steven. Deleuze's Encounter With Whitehead. [200-]. Disponível em: <http://ftp.shaviro.com/Othertexts/DeleuzeWhitehead.pdf>. Acesso em: 16 jun. 2014.

Recebido em: 26/06/2014

Aprovado em: 01/10/2014 